\title{
Potencialidade do Moodle no gerenciamento de bolsistas em uma Universidade
}

\section{Federal}

\author{
Potentiality of Moodle in managing fellows at a Federal University \\ Potencialidad de Moodle en la gestión de becarios en una Universidad Federal
}

Recebido: 25/03/2021 | Revisado: 30/03/2021 | Aceito: 02/04/2021 | Publicado: 04/04/2021

João Juliano Monteblanco Castro
ORCID: https://orcid.org/0000-0001-7574-036X
Universidade Federal de Santa Catarina, Brasil
E-mail: monteblancors@gmail.com
Juliane Paprosqui
ORCID: https://orcid.org/0000-0002-3034-2453
Universidade Federal de Santa Maria, Brasil
E-mail: juliane_paprosqui@ @otmail.com
Liziany Müller Medeiros
ORCID: https://orcid.org/0000-0001-7325-6611
Universidade Federal de Santa Maria, Brasil
E-mail: lizianym @ hotmail.com
Ivanio Folmer
ORCID: https://orcid.org/0000-0002-7433-6434
Universidade Federal de Santa Maria, Brasil
E-mail: ivaniofolmer@yahoo.com.br
Gabriella Eldereti Machado
ORCID: https://orcid.org/0000-0001-5908-4753
Universidade Federal de Santa Maria, Brasil
E-mail: gabriellaeldereti@ @mail.com

\begin{abstract}
Resumo
$\mathrm{O}$ artigo que se apresenta discorre sobre a potencialidade do uso do Ambiente Virtual de Ensino-Aprendizagem (AVEA) Moodle como ferramenta de apoio à gestão de bolsas da Universidade Aberta do Brasil (UAB), inserido na Universidade Federal de Santa Maria (UFSM), que é gerido pelo Núcleo de Tecnologia Educacional (NTE). O trabalho foi desenvolvido sob uma abordagem de pesquisa qualitativa, em um contexto de estudo de caso. O públicoalvo foram os coordenadores gerais (22) e os coordenadores de tutoria (05) dos cursos da UAB/UFSM. Como instrumento de coleta de dados foi adotado um questionário, com 21 questões abertas e fechadas. Os dados revelados mostram a potencialidade de uso do Moodle na mediação do sistema de bolsas e a implementação de um tutorial que auxilie os coordenadores nos momentos de gestão de pagamento de bolsas. É uma ferramenta importante que torna o processo mais ágil e sem tantos entraves burocráticos. A utilização do AVA Moodle torna o processo mais fluído, democrático e transparente.
\end{abstract}

Palavras-chave: Democrático; AVEA Moodle; Gestão; Tutorial; Ensino.

\begin{abstract}
The present article discusses the potential of using the Virtual Teaching-Learning Environment (AVEA) Moodle as a tool to support the management of scholarships at the Open University of Brazil (UAB), inserted at the Federal University of Santa Maria (UFSM), which is managed by the Educational Technology Center (NTE). The work was developed under a qualitative research approach, in a case study context. The target audience was the general coordinators (22) and the tutoring coordinators (05) of the courses at UAB / UFSM. As a data collection instrument, a questionnaire was adopted, with 21 open and closed questions. The revealed data show the potential of using Moodle in the mediation of the scholarship system and the implementation of a tutorial that helps the coordinators in the management of scholarship payment. It is an important tool that makes the process more agile and without so many bureaucratic obstacles. The use of AVA Moodle makes the process more fluid, democratic and transparent.
\end{abstract}

Keywords: Democratic; AVEA Moodle; Management; Tutorial; Teaching.

\section{Resumen}

El presente artículo discute el potencial de utilizar el Ambiente Virtual de Enseñanza-Aprendizaje (AVEA) Moodle como herramienta de apoyo a la gestión de becas en la Universidad Abierta de Brasil (UAB), insertada en la Universidad Federal de Santa María (UFSM), que es administrado por el Centro de Tecnología Educativa (NTE). El trabajo se desarrolló bajo un enfoque de investigación cualitativa, en un contexto de estudio de caso. El público 
objetivo fueron los coordinadores generales (22) y los coordinadores de tutorías (05) de los cursos de la UAB / UFSM. Como instrumento de recolección de datos se adoptó un cuestionario, con 21 preguntas abiertas y cerradas. Los datos revelados muestran el potencial del uso de Moodle en la mediación del sistema de becas y la implementación de un tutorial que ayude a los coordinadores en la gestión del pago de becas. Es una herramienta importante que hace que el proceso sea más ágil y sin tantos obstáculos burocráticos. El uso de AVA Moodle hace que el proceso sea más fluido, democrático y transparente.

Palabras clave: Democrático; AVEA Moodle; Administración; Tutorial, Ensenãnza.

\section{Introdução}

No Brasil, a Educação a Distância (EaD) surge como possibilidade de difusão e de democratização da educação de qualidade e como uma das melhores opções para a inclusão social, visando responder às demandas pleiteadas pela evolução da sociedade e dos processos de comunicação (Lessa, 2011). A Lei de Diretrizes e Bases da Educação (LDB), n. ${ }^{\circ}$ 9.394, de dezembro de 1996, abriu a possibilidade de ofertar a EaD para todos os níveis e modalidades de ensino (Brasil, 2021).

A Universidade Aberta do Brasil (UAB) é um sistema integrado que propicia a articulação, a interação e a efetivação de iniciativas que estimulam a parceria dos três níveis governamentais - federal, estadual e municipal - com as universidades públicas, para oferecer, cursos de nível superior, por meio da $\mathrm{EaD}$ (Brasil, 2021). O público em geral é atendido, porém, os professores que atuam na Educação Básica têm prioridade de formação (Brasil, 2021). A qualidade da EaD está diretamente relacionada com a qualidade e integração das ações de diferentes sujeitos que compõem o Sistema UAB.

A Universidade Federal de Santa Maria (UFSM) atua no Sistema UAB, ofertando cursos a distância mediados pelo ambiente virtual de ensino aprendizagem (AVEA) Moodle (Modular Object Oriented-Dynamic Environment). Atualmente, a instituição possui 10 cursos de graduação com oferta em andamento para 38 Polos de apoio presencial (NTE, 2021). O Moodle também é utilizado na UFSM como apoio para disciplinas do ensino presencial, para programas de capacitação para professores e tutores e como auxílio na gestão de bolsas (UFSM, 2016).

O documento do Ministério da Educação, Referenciais de Qualidade para Educação a Distância, destaca a importância do processo de gestão para o desenvolvimento de um bom sistema de educação a distância (Brasil, 2007; Mill \& Brito, 2009). Entre os sistemas em que a UAB é gerenciada e assistida, destaca-se o Sistema de Gestão de Bolsas - SGB, que é utilizado para gerir bolsas de auxílio fornecidas pelos programas que participam da política de incentivo à educação do governo federal.No caso da UAB, ele é desenvolvido e mantido pela Diretoria de Educação a Distância da CAPES (Brasil, 2017; Coelho et al., 2014).

O sistema UAB financia o pagamento de bolsas para a equipe multidisciplinar dos cursos, o que envolve Coordenador UAB, Coordenador Adjunto UAB, Coordenadores de Curso, Coordenadores de Tutoria, Professor Formador I, Professor Formador II, Professor Conteudista I, Professor Conteudista II e Tutores (Brasil, 2021). O gerenciamento das Bolsas UAB, após julho de 2011, é responsabilidade da Coordenação de Aperfeiçoamento de Pessoal de Nível Superior (CAPES), e no SGB, o coordenador UAB cadastra e homologa os bolsistas de todos os cursos e programas de suas IES (Brasil, 2021).

Coelho et al. (2014) revelam que, todos os meses, as coordenações dos cursos enviam um memorando solicitando que a coordenação UAB da IES efetue a liberação dos bolsistas autorizados no SGB, conforme um quantitativo de cotas baseados em carga horária e/ou quantidade de alunos. Essa tarefa exige dos coordenadores UAB a execução de um processo de conferência de cada memorando e o respectivo lançamento de informações dos bolsistas, um a um, no SGB (Coelho et al., 2014).

Mill e Brito (2009) ressaltam que a gestão na educação a distância, assim como na presencial, se refere à ação de planejar, organizar, coordenar e controlar: espaço, tempo, dinheiro, instalações, pessoas e informações, não perdendo de foco o aspecto pedagógico, já que, em ambas as modalidades essa é a finalidade, mas, no caso da gestão da $\mathrm{EaD}$, certas 
especificidades devem ser analisadas com atenção. Assim, Coelho et al. (2014) comentam que cada instituição integrante do sistema UAB, ao seu ritmo, foi desenvolvendo processos para que fosse possível atender às demandas exigidas pela EaD.

Diante desse cenário, faz-se importante que as rotinas administrativas se integrem às tecnologias disponíveis. O Moodle, segundo Magnagnago et al. (2015), foi desenvolvido originalmente para auxiliar na criação de cursos online, focando na interação e criação colaborativa de conteúdo, mas seu conjunto de ferramentas (recursos e atividades) disponibilizadas, tais como fóruns, chats, questionários, wiki, tarefas, etc., amplia a perspectiva de uso.

A flexibilidade de possibilidades do uso Moodle pode permitir que ele tenha potencialidade de ser utilizado como uma ferramenta de apoio à gestão administrativa, para otimizar as rotinas de autorização das bolsas. O Moodle viabiliza a mediação entre os sujeitos envolvidos no pagamento de bolsas CAPES da UAB, dando transparência e agilidade a este processo.

Como parte do repensar sobre o processo de controle de informações dos bolsistas do Sistema UAB, é importante contextualizar como acontecem os procedimentos de solicitação e liberação das bolsas (Coelho et al., 2014). Assim, o objetivo desse trabalho é analisar e refletir sobre a potencialidade do AVEA Moodle na mediação do sistema de gerenciamento de bolsistas da Universidade Aberta do Brasil na Universidade Federal de Santa Maria.

\section{Metodologia}

O trabalho foi realizado no Núcleo de Tecnologia (NTE) da Universidade Federal de Santa Maria, no ano de 2018. Este Núcleo tem como finalidade executar as políticas definidas pelas instâncias competentes da UFSM, conforme regimento, nas modalidades educacionais mediadas por tecnologias em cursos de ensino básico, profissionalizante, graduação, programas de extensão, atuando como agente de inovação dos processos de ensino-aprendizagem bem como no fomento à incorporação das Tecnologias de Informação e Comunicação aos projetos pedagógicos da UFSM (NTE, 2018).

O NTE possui um setor administrativo, que é responsável pelos processos administrativos, tais como organização e controle de viagens, cadastramento e autorização das bolsas CAPES do sistema UAB pelo Sistema de Gestão de Bolsas (SGB), gerenciamento das cotas referentes aos cursos da UAB/UFSM e dos projetos UAB. Assim, o NTE faz o gerenciamento das autorizações de pagamento das bolsas CAPES do sistema UAB/UFSM, destinadas ao Coordenador UAB, Coordenador Adjunto UAB, Coordenadores de Curso, Coordenadores de Tutoria, Professores Formadores, Professores Conteudistas e Tutores.

O trabalho foi desenvolvido sob uma abordagem de pesquisa qualitativa, em um contexto de estudo de caso.

Para Gerhard e Silveira (2009), a pesquisa qualitativa preocupa-se com os aspectos da realidade que não podem ser quantificados, compreendendo e explicando as dinâmicas das relações sociais. Esse tipo de abordagem preocupa-se em aprofundar conhecimentos de determinado grupo social, tendo como importância principal produzir novas informações. Creswell (2007) afirma que, na pesquisa qualitativa, os pesquisadores fazem coleta de dados em um contexto natural, sensível às pessoas e aos lugares de estudo.

Já os estudos de caso podem ser usados para descrever e analisar uma unidade social, levando em conta as múltiplas dimensões e sua dinâmica natural (André, 2013). Para Ventura (2007), o estudo de caso, é entendido como uma modalidade de pesquisa, como uma metodologia ou como a escolha de um objeto de estudo definido pelo interesse em casos individuais.

O público-alvo do presente trabalho foram os coordenadores gerais (22) e os coordenadores de tutoria (05) dos cursos da UAB/UFSM no ano de 2018. Como instrumento de coleta de dados, foi adotado um questionário tipo survey. Utilizou-se o ambiente Moodle, na disciplina nomeada de "bolsas" (à qual todos os coordenadores gerais e de tutoria têm acesso - Figura 1), pela opção "mensagens", no mês de julho de 2018, quando foi enviado o convite para participação da pesquisa através do preenchimento de um questionário. 
Figura 1 - AVEA Moodle - disciplina nomeada de bolsas, onde são indicados os bolsistas UAB pelos coordenadores de curso

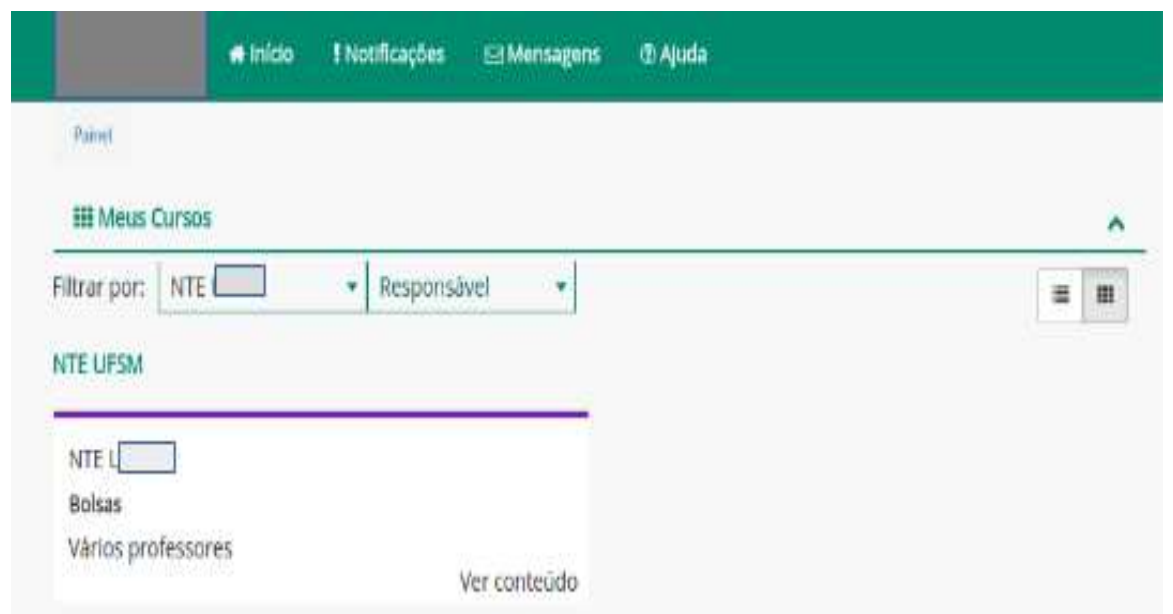

Fonte: Adaptado pelos autores do site NTE/UFSM

Uma semana após o envio, foram realizadas ligações telefônicas para os coordenadores, reforçando o convite à resposta do questionário. A elaboração do questionário se deu na ferramenta Google Formulários e teve 21 questões abertas e fechadas, sendo acessado pelo link: (https://docs.google.com/forms/d/e/1FAIpQLSclsrz5fD2M6DntgLbrOyWn FyBxYRp6ojU9F_LxetP7wvXTgw/viewform?usp=sf_link). O questionário levou em consideração os seguintes aspectos: perfil dos coordenadores gerais e de tutoria, avaliação de informações como: documentos necessários para pagamento de bolsas UAB, informações disponibilizadas pelo NTE e uso do Moodle como mediador da indicação do pagamento de bolsas UAB/CAPES.

\section{Resultados e Discussão}

A aplicação do questionário possibilitou identificar o perfil dos Coordenadores de curso e de Tutoria atuantes no processo de gestão educacional de bolsas CAPES do sistema UAB/UFSM, bem como analisar a potencialidade de utilização do AVEA Moodle na mediação do sistema de gerenciamento de bolsistas da UAB/UFSM e as necessidades de melhoria.

O questionário foi submetido a um total de 27 (vinte e sete) Coordenadores de Curso e de Tutoria, sendo que, destes, 22 (vinte e dois) responderam, o que representa um percentual de $81,5 \%$ do total.

Sequencialmente apresenta-se as informações mais relevantes, que servem para auxiliar no entendimento dos sujeitos envolvidos, e também na proposição de mecanismos para melhorar o processo de gestão educacional que utilizam as potencialidades do AVEA Moodle como mediador desse processo.

$\mathrm{Na}$ pergunta inicial, o questionário buscou conhecer a faixa etária e o sexo dos coordenadores de curso e dos coordenadores de tutoria, conforme Gráfico 1: 
Gráfico 1 - Gráficos de gênero e idade dos coordenadores.
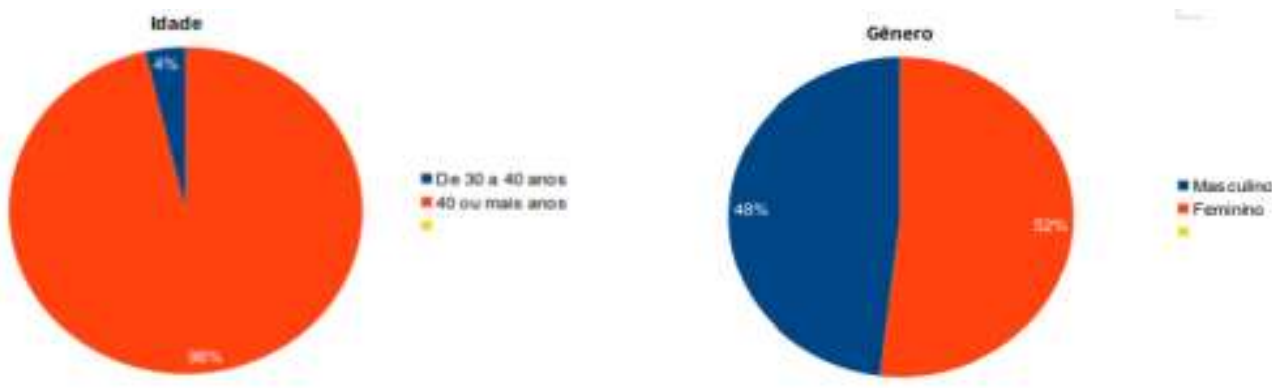

Fonte: Autores.

Observou-se que grande parte dos sujeitos envolvidos é do sexo feminino e possui idade igual ou superior a 40 anos. Esses dados contrariam aqueles apontados pelo IBGE (2018) quando se trata de gênero, pois a incidência de mulheres em cargos administrativos é $12 \%$ menor que a dos homens e os cargos com maiores salários ainda são integrados por homens nas instituições. Apontam também, que docentes do sexo feminino estão mais concentradas em determinadas áreas de conhecimento. As mulheres são a maioria nos bancos universitários, 57,1\%, porém quando se trata de cargos de comando esses dados se invertem (IBGE, 2018).

O fator idade talvez esteja atrelado aos profissionais com mais tempo no exercício da docência fazendo com que possam e queiram se dedicar a outros formatos educacionais, experimentando novas possibilidades. Fidelis Tomelin e Nones Tomelin (2017) ressaltam que a maioria dos coordenadores de curso são professores que migram de atividades docentes e passam a realizar atividades pedagógicas e administrativas, sendo que a maioria dos coordenadores é do sexo feminino, acima dos 40 anos de idade e tem de 1 a 5 anos de experiência na função desempenhada na UAB.

Percebe-se, na Figura 2, que as áreas atendidas pela educação a distância na UFSM são múltiplas, o que, de certa forma, faz com que se tenha um público de coordenadores bem heterogêneo nas áreas de conhecimento.

Figura 2 - Cursos de atuação dos entrevistados.

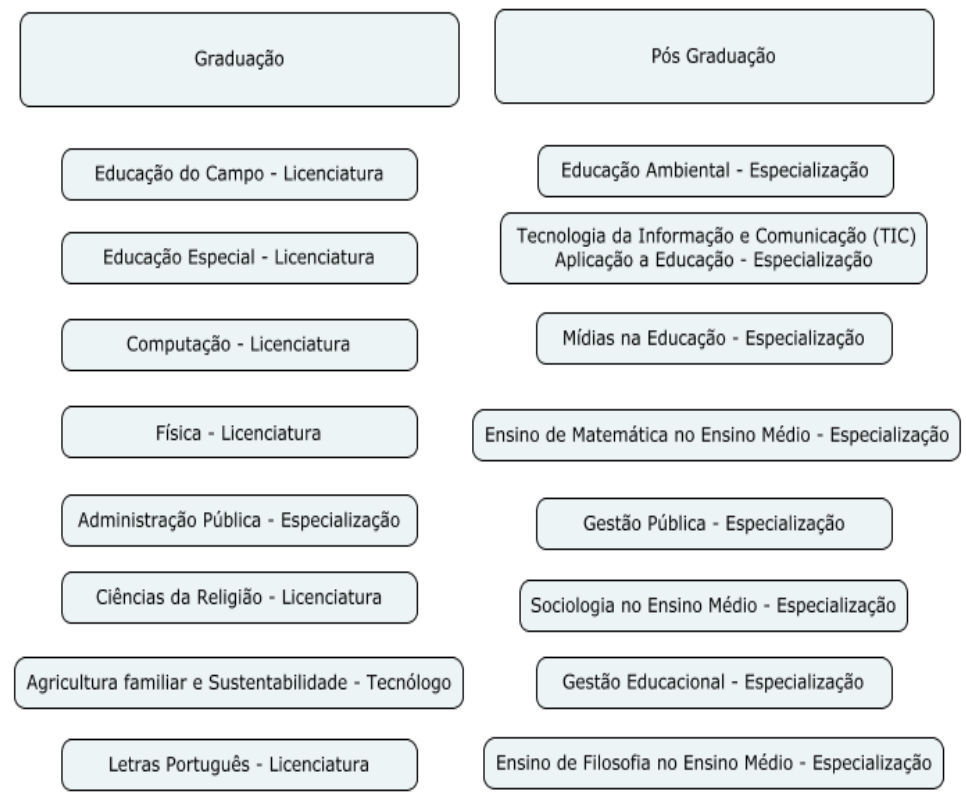

Fonte: Autores.

Quanto à função desempenhada no sistema UAB/UFSM, a maioria é coordenador de curso (Gráfico 2), ficando 
apenas um percentual pequeno de $19 \%$ com coordenadores de tutoria, o que chama atenção nesse aspecto é o gráfico seguinte (Gráfico 3) o qual perguntava se o memorando de indicação de bolsas é feito via sistema Moodle, o percentual dos que encaminham via o ambiente é o mesmo percentual de coordenadores de curso que responderam ao questionário, sugerindo assim, que os coordenadores de curso têm o costume de encaminhar o memorando via ambiente virtual, demostrando assim que a utilização do ambiente para este fim é aceita e utilizada na instituição. Coelho et al. (2014) revelam que os coordenadores dos cursos a distância enviam, até o décimo dia útil do mês, um memorando com a lista de bolsistas autorizados a receber naquele mês para os coordenadores UAB, que fazem todo o processo de arquivamento.

Gráfico 2 - Função de atuação no sistema UAB.

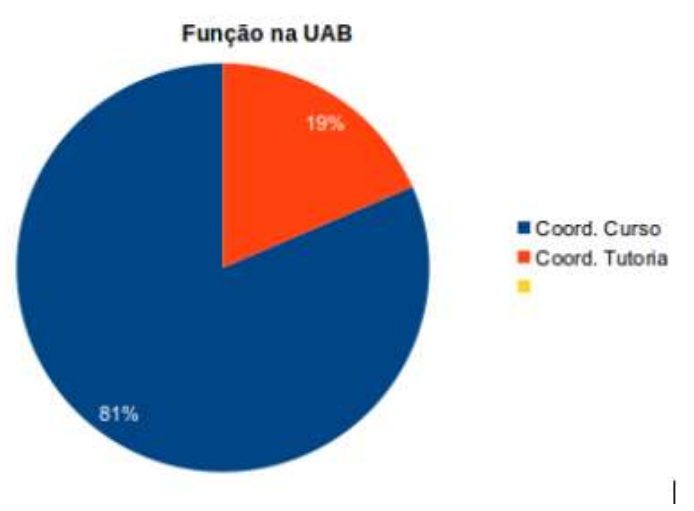

Fonte: Autores.

Gráfico 3 - Envio dos memorandos dos bolsistas CAPES do sistema UAB/UFSM pelo AVEA Moodle.

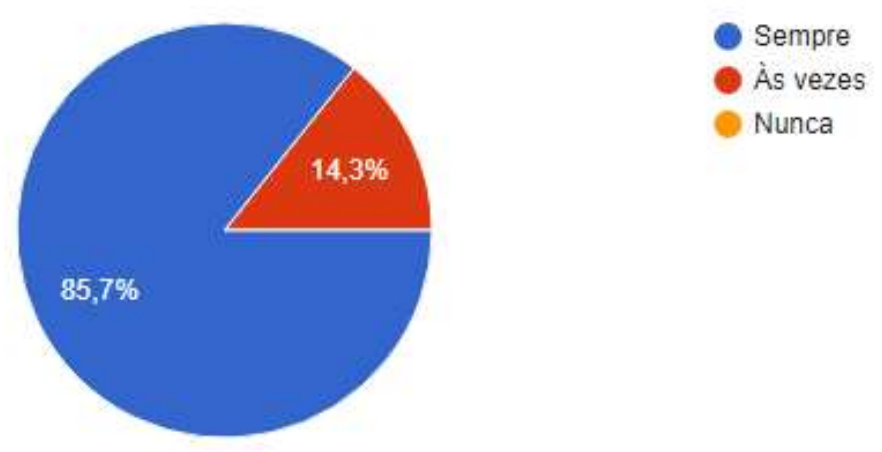

Fonte: Autores.

Quando questionados sobre as possíveis dificuldades no preenchimento do memorando solicitado para indicação de pagamentos dos bolsistas CAPES do sistema UAB/UFSM a maioria, perfazendo um total de 95,2\%, (gráfico 4), disseram não ter dificuldades, evidenciando que os coordenadores já estão acostumados com as rotinas burocráticas a que os sistemas de ensino são submetidos. Coelho et al. (2014) destacam que é muito comum acontecer atrasos ou reenvio dos relatórios por causa de erros nos memorandos com bolsistas UAB que não foram incluídos ou que devem ser retirados. 
Gráfico 4 - Dificuldades no preenchimento do memorando de pagamento de bolsas.

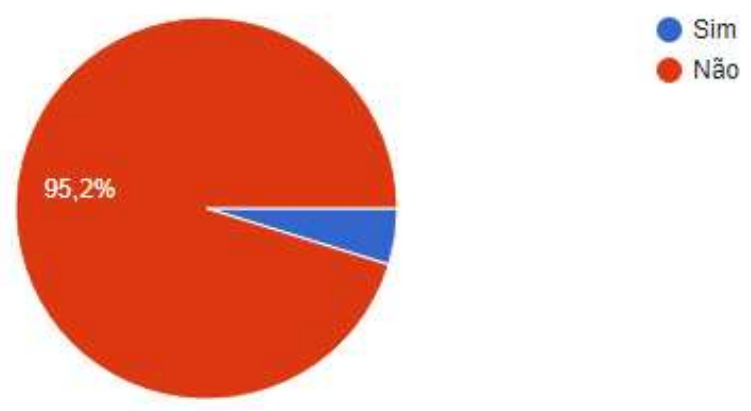

Fonte: Autores.

No que tange ainda o questionamento sobre dificuldades no preenchimento do memorando de pagamento de bolsas, uma dificuldade relatada pode ser vista no Gráfico 4 e na Figura 4, nos quais observa-se que a dificuldade não necessariamente está no preenchimento do memorando, mas, sim, nas informações referentes ao preenchimento dos documentos por parte dos bolsistas e a consequente entrega da documentação comprobatória. E também informações referentes ao quantitativo de bolsas disponíveis para o curso. Coelho et al. (2014) informam que todos os cursos possuem uma cota de bolsas, que não pode ser ultrapassada, e esse controle é feito pelo coordenador do curso, a partir da informação do coordenador UAB. Os autores também mencionam que, após o recebimento dos memorandos dos coordenadores de curso, o coordenador UAB ou adjunto acessa o SGB e confere os relatórios enviados, autorizando ou não a bolsa de cada um dos bolsistas UAB, sendo que esse é um processo crítico, pois uma falha impacta diretamente o bolsista, e sua situação apenas poderá ser resolvida no mês seguinte, quando a DED/CAPES disponibiliza um lote especial para resolver erros.

Figura 3 - Dificuldades relatadas dos coordenadores do curso no questionário submetido

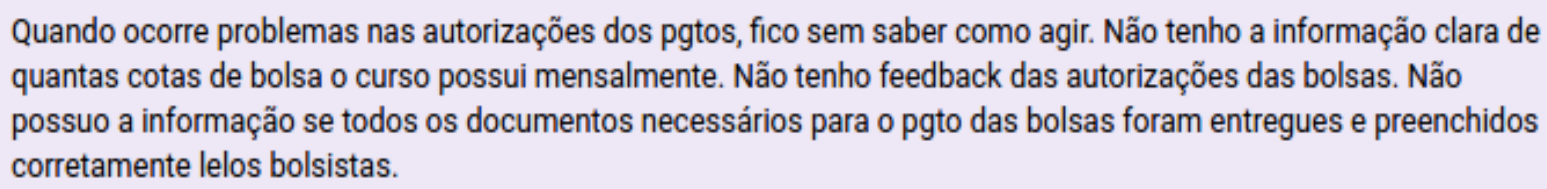

Fonte: Autores, a partir do site NTE/UFSM.

Quando questionados sobre dificuldades no acesso ao Moodle as respostas são unânimes em dizer que não encontram dificuldades relativas a isso, dado que aponta para a internalização do conhecimento acerca do ambiente virtual, demonstrando que os cursos de capacitações realizados pelo NTE e a consequente utilização deste ambiente pela Universidade Federal de Santa Maria fez com que, ao passar do tempo, a utilização deste já não tivesse mais resistência nem entraves, pelo menos, por parte dos respondentes esses dados também reafirmam a importância em utilizar o próprio ambiente Moodle para o gerenciamento do pagamento de bolsistas na Instituição.

Assim, pode-se entender que o sistema de gerenciamento de bolsas criado pelo NTE/UFSM corrobora com o mencionado por Mill e Brito (2009), que na EaD há maior fragmentação do trabalho, o que exige atenção especial do gestor para que existam adequadas articulações entre as partes envolvidas. Os autores ressaltam que, para que o processo de ensinoaprendizagem na educação a distância ocorra, é preciso que a gestão contemple as questões pedagógicas, administrativas, 
tecnológicas etc, e, quando se tratar de uma proposta de formação robusta como cursos de graduação, a gestão bem organizada significa envolver uma equipe gestora e não apenas por uma pessoa cuidando de todas as atividades envolvidas.

Gráfico 5 - Dificuldades de acesso ao AVEA Moodle.

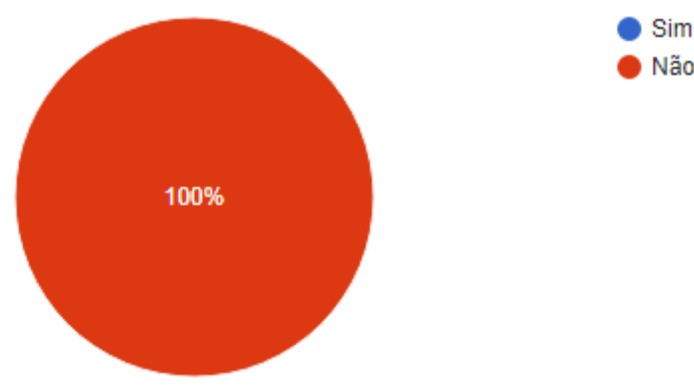

Fonte: Autores.

Figura 4 - AVEA Moodle - Tarefa envio de memorandos, onde são indicados os bolsistas UAB pelos coordenadores de curso.

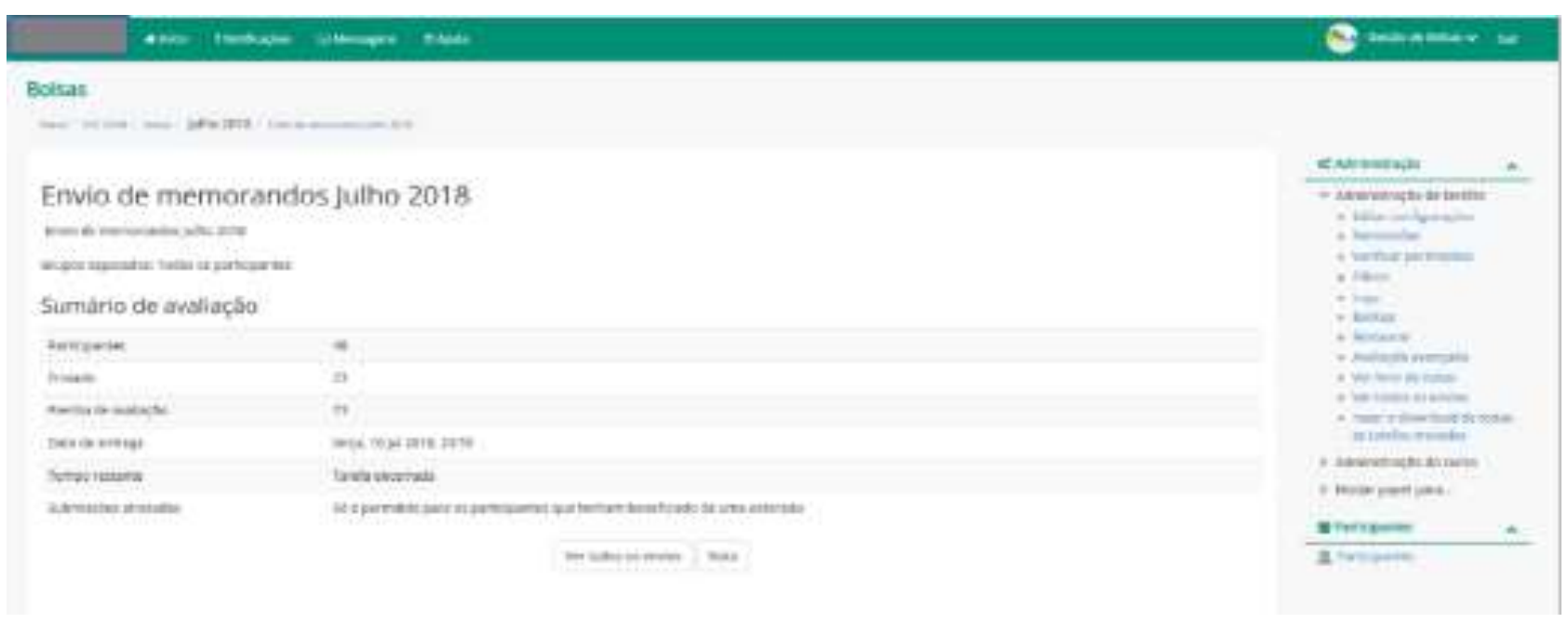

Fonte: Autores, a partir do site do NTE/UFSM.

Quanto à questão sobre a interpretação das informações (Gráfico 6) disponibilizadas na disciplina "bolsas" no ambiente Moodle, $62 \%$ responderam que conseguem interpretar, porém em contrapartida, 38\%, um percentual considerável, disseram interpretar essas informações em parte. Este dado sugere que, por vezes, se tem dificuldades nesse quesito, levando a entender que podem ocorrer informações dúbias. Nesse sentido, um instrumento que ofereça as informações de forma clara através de um tutorial parece ser positivo uma vez que, poderá sanar possíveis dúvidas de forma rápida e concisa. 
Gráfico 6 - Interpretação das informações disponibilizadas no AVEA Moodle.

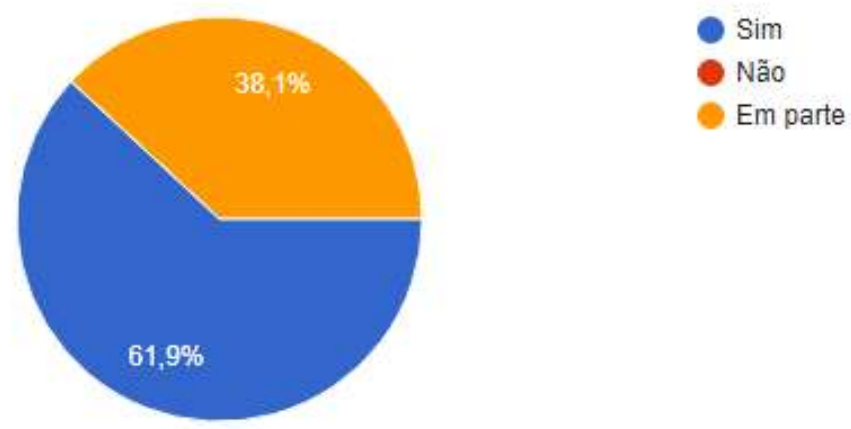

Fonte: Autores.

Nenhum dos participantes respondeu que não consegue interpretar as informações disponibilizadas.

Sobre a importância da utilização do ambiente Moodle no processo de Gestão Educacional de bolsas CAPES do sistema UAB/UFSM, a maioria entende ser importante, perfazendo um total de $91 \%$, e nenhum dos entrevistados acredita que a utilização do ambiente Moodle não é importante (Gráfico 7), dado que remete mais uma vez para a utilização do ambiente já estar internalizada nas práticas docentes dos pesquisados, se mostrando um ambiente seguro e eficaz também para gestão educacional. Dados que corroboram com essa questão foram observados na pergunta que buscava saber sobre as dificuldades no acesso à documentação no site do NTE, quando $86 \%$ não encontraram dificuldades, demostrando, desta forma, que a interface utilizada pelo núcleo é acessível e amigável para os usuários.

Gráfico 7 - Importância do uso do AVEA Moodle na gestão de bolsas.

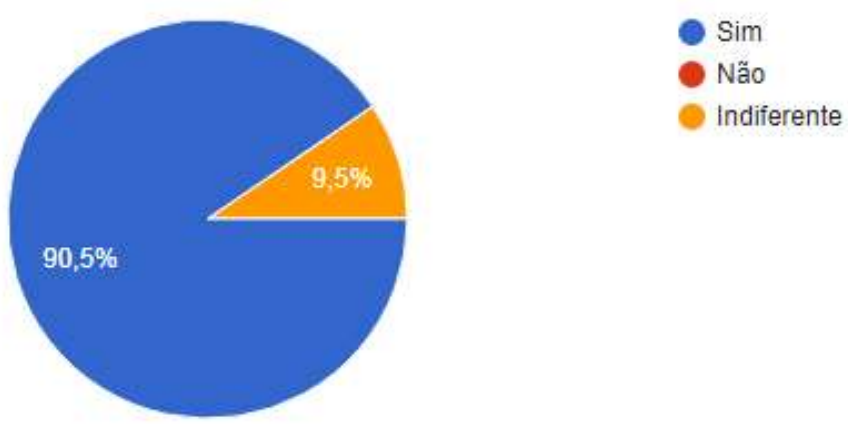

Fonte: Autores.

Quanto às dúvidas possíveis sobre a documentação necessária para o cadastro de bolsistas, a maioria, 81\%, demonstrou não ter dificuldades, isso pode ser entendido pelo fato da documentação ser auto-explicativa, trazendo os elementos essenciais no preenchimento e também indo ao encontro das informações referentes a isso disponibilizadas no site do NTE. 
Gráfico 8 - Dúvidas sobre a documentação necessária para cadastramento.

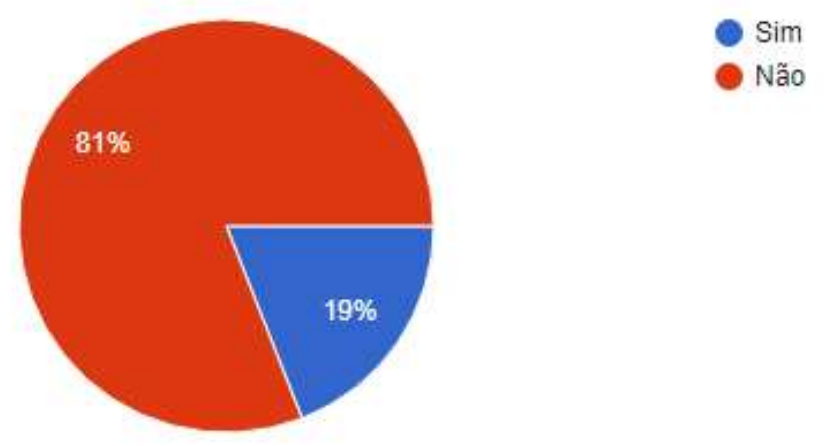

Fonte: Autores.

Também não foi notada dificuldade no preenchimento da documentação cadastral, conforme demonstra o Gráfico 9 , pois $86 \%$ dos respondentes informam que não têm dificuldades nesse aspecto. Esses dados refletem a importância de ter uma equipe no núcleo de tecnologia disponível para sanar dúvidas e também das importantes informações disponíveis em sua página web.

Gráfico 9 - Dificuldades no preenchimento da documentação cadastral.

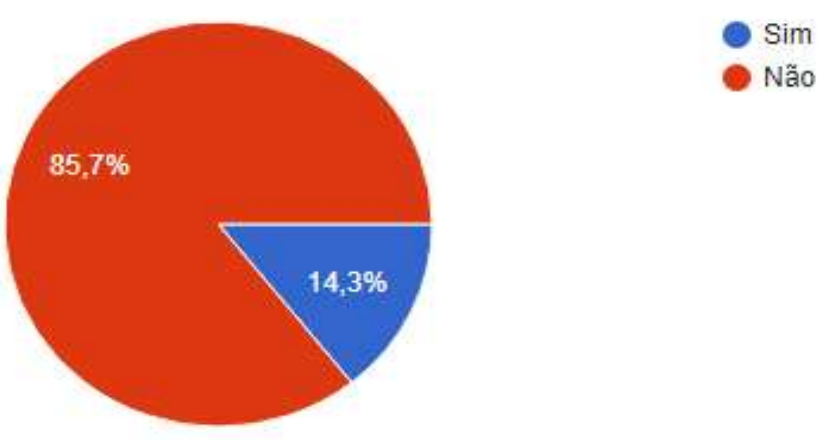

Fonte: Autores.

Em se tratando do conhecimento dos prazos até a liberação das bolsas na conta corrente, ainda se tem dúvidas referentes a isso, pois, de acordo com os resultados apresentados, $14 \%$ dos entrevistados não tem conhecimento, $29 \%$ tem em parte e 57\% conhecem o processo. Dados que fazem refletir sobre a importância de tornar o processo do início ao fim o mais transparente possível, uma vez que, em resultados anteriores, não foi detectada dificuldade em cadastrar bolsistas e nem na documentação exigida. Neste aspecto, os dados revelam que o processo não é conhecido do início ao fim, sendo necessário ser mais transparente, fato que poderia ser sanado com um tutorial explicativo.

Já quando questionados sobre o conhecimento de lotes complementares, conforme o Gráfico 10, a maioria diz ter conhecimento, $76 \%$ informam que conhecem esse processo, fato que pode ser interpretado pelas inúmeras vezes que são pagas bolsas em lotes dessa natureza. 
Gráfico 10 - Conhecimento dos Lotes Complementares.

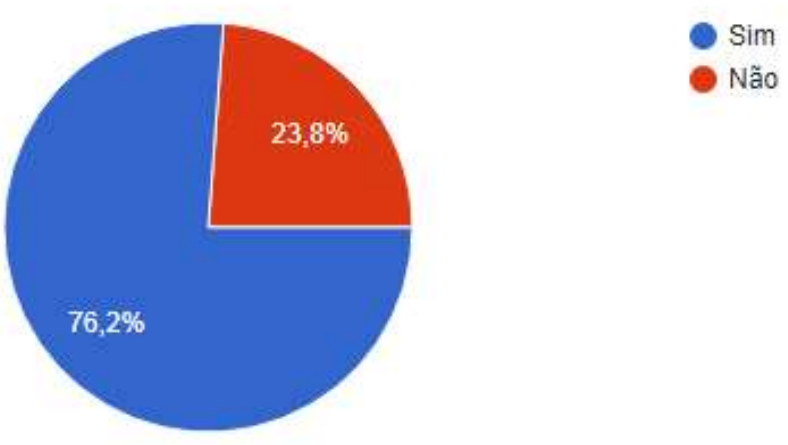

Fonte: Autores.

Quando indagados sobre a eficiência de um tutorial como ferramenta de auxílio e minimização de dúvidas, o Gráfico 11 mostra que a maioria, 91\%, acredita que este seria importante, o que faz refletir que os mesmos acreditam que os coordenadores que venham a se dedicar a essa tarefa já tenham um meio disponível que os auxilie e não fiquem com inúmeras dúvidas que poderiam ser sanadas de imediato. Mill e Brito (2009) evidenciam que geralmente, as universidades não estão preparadas para a reestruturação institucional que a $\mathrm{EaD}$ exige, assim a inteligência estratégica é essencial nesta fase de implantação e institucionalização da EaD nas (já enferrujadas) universidades brasileiras.

Gráfico 11 - Tutorial como ferramenta de auxílio e minimização de dúvidas.

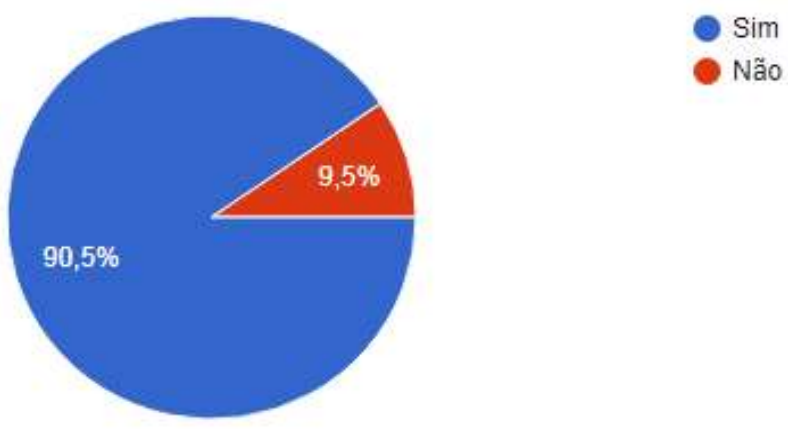

Fonte: Autores.

No que diz respeito a cursos de capacitação sobre gestão educacional de bolsas CAPES UAB/UFSM a intenção em participar ainda é da maioria, 62\% tem essa intenção, porém, também é expressivo o número daqueles (as) que não tem intenção em participar, dado que comprova que o tutorial para auxílio nas dúvidas é de grande valia.

No que diz respeito à participação em capacitação promovida pelo NTE, também se nota uma divisão, ficando apenas alguns pontos percentuais de quem participa, 57\%, daqueles que não participam, 43\%. Para esses dados, pode-se entender que, como são gestores, ou seja, coordenadores de curso, os mesmos já devem ter realizado diversos cursos ofertados pelo NTE, sendo vencida as dificuldades iniciais no que diz respeito principalmente com a utilização do Moodle não veem mais necessidade em realizar tais capacitações. 


\section{Considerações Finais}

Os dados revelados pela pesquisa mostram a potencialidade de utilizar o Moodle na mediação do sistema de bolsas e a implementação de um tutorial que auxilie os coordenadores atuais e futuros nos momentos de gestão de solicitação de pagamento de bolsas. Mostra-se como uma ferramenta importante tornando o processo mais ágil e sem tantos entraves burocráticos ocasionados por falta de informação ou informações erradas. A utilização do AVA Moodle torna o processo mais fluído, transparente e democrático.

Quanto ao tutorial demonstrativo dos processos utilizados na gestão educacional de autorização das bolsas CAPES do sistema UAB/UFSM, este é um instrumento que vai ao encontro de necessidades pontuais, simplificando processos e também descongestionando setores que já possuem inúmeras outras atividades burocráticas. Esse instrumento também desonera trabalhadores. Outro ponto extremamente positivo é a temporalidade/disponibilidade da informação, uma vez que, esta não ficará com um ou outro coordenador, mas sim estará acessível para todos, pois, é difícil ter em alguém a totalidade deste processo. Também leva-se em consideração que as informações sobre os processos de gestão educacional das bolsas CAPES do sistema UAB/UFSM não ficarão centralizadas na figura de uma só pessoa, um só servidor ou bolsista que trabalhe no setor de bolsas do Núcleo de Tecnologia Educacional da UFSM, não gerando assim atrasos ou dificuldades quando a pessoa que detém as informações, por algum motivo, esteja em período de férias, licenças, etc.

Apresentar o AVEA Moodle na mediação de processos de gestão educacional das bolsas CAPES do sistema UAB/UFSM e a possibilidade de ter um tutorial demonstrativo dos processos utilizados na gestão educacional de autorização das bolsas CAPES do sistema UAB/UFSM que auxilie na logística da gestão em EaD na Universidade Federal de Santa Maria, pelo sistema da UAB, foi a intenção do trabalho apresentado. Pode-se afirmar com a pesquisa que a utilização do AVEA Moodle bem como a elaboração de um tutorial muito tem a agregar nos fazeres diários de coordenadores de curso e tutoria e também dos secretários dos cursos envolvidos, ajudando também na logística do próprio Núcleo de Tecnologia da UFSM sendo mais um elemento que colabora com a gestão de processos agregando dinamicidade, democratização da informação e transparência, principalmente na educação a distância. Utilizando-se dessas ferramentas de auxílio e gestão pretende-se agregar segurança ao processo, principalmente por se tratar de recursos públicos e de grande responsabilidade.

Assim, a pesquisa corrobora com Mill e Brito (2009), que citam que a implementação de EaD de forma equiparada à educação presencial exige mudança em toda a estrutura organizacional da instituição, tanto em termos de recursos materiais, humanos, financeiros, informacionais e espaço-temporais. Os autores relatam que tudo isto precisa ser bem administrado pelo gestor educacional da $\mathrm{EaD}$ em suas decisões de planejamento, organização, direção e controle dos processos. Esse estudo viabiliza uma grande mudança na cultura dentro do ambiente de trabalho, uma vez que essa ampliação e divulgação das informações é um fato nunca adotado pelo setor responsável pela gestão educacional de bolsas CAPES do sistema UAB/UFSM. A transparência e a democratização das informações muito tem a enriquecer e melhorar o trabalho para toda sociedade. O trabalho revelou outros potenciais que o Moodle assume diante das necessidades da IES, acredita-se que ainda tenha muitas ferramentas deste ambiente virtual que ainda não foi revelada seu potencial para gestão da educação e auxílio no processo de democratização do ensino.

\section{Referências}

André, M. (2019). O que é um estudo de caso qualitativo em educação? Revista Da FAEEBA - Educação E Contemporaneidade,22(40), 95-103. https://doi.org/10.21879/faeeba2358-0194.2013.v22.n40.p95-103

Bach-y-Rita, P. (1972). Brain Mechanisms in Sensory Substitution. Academic Press, 1972. 182 p.

Bach-y-Rita, P. \& Kercel, S.W. (2003). Sensory substitution and the human-machine interface. Trends in Cognitive Sciences, 7, 541-546.

Belarmino, J. (2004). Aspectos Comunicativos da Percepção Tátil: a escrita em relevo como mecanismo semiótico da cultura. 2004. Tese (doutorado) Programa de Pós-Graduação em Comunicação e Semiótica, Pontifícia Universidade Católica de São Paulo, São Paulo, BR-SP. 
Research, Society and Development, v. 10, n. 4, e32710414269, 2021

(CC BY 4.0) | ISSN 2525-3409 | DOI: http://dx.doi.org/10.33448/rsd-v10i4.14269

Brasil. (2021). Ministério da Educação (MEC). Universidade Aberta do Brasil (UAB) http://portal.mec.gov.br/uab

Brasil. (2021). Casa Civil. Lei no 9394, de 20 de dezembro de 1996. http://www.planalto.gov.br/ccivil_03/leis/19394.htm.

Brasil.(2021). Ministério da Educação (MEC). Referenciais de Qualidade para Educação a Distância. http://portal.mec.gov.br/seed/arquiv os/pdf/legislacao/refead1.pdf.

Brasil. (2021). Ministério da Educação (MEC). Educação Superior: Portaria regulamenta bolsas para professores UAB. http://portal.mec.gov.br/index.php?option=com_docman\&view=download\&alias=49711 -port-capes-183-uab-24out-pdf\&category_slug=outubro-2016pdf\&Itemid=30192

Coelho, F. M.; Junior, J. M. C. \& Nunes, V. B. (2014) SGBL - Sistema de gerenciamento de bolsistas local da UAB no CEAD/IFES. http://www.abed.org.br/hotsite/20-ciaed/pt/anais/pdf/77.pdf

Creswell, J. W. (2007). Projeto de Pesquisa: Métodos Qualitativo, Quantitativo e Misto. (2a ed.), Artmed, 248 p.

Gatti, B. A. (2005). Grupo focal na pesquisa em ciências sociais e humanas. Liber Livro Editora.

Gerhardt, T.\& Silveira, D. (organizadoras). (2009). Métodos de Pesquisa. Editora da UFRGS.

IBGE - Instituto Brasileiro de Geografia e Estatística (2018). Estatísticas de gênero: responsabilidade por afazeres afeta inserção das mulheres no mercado de trabalho. https://agenciadenoticias.ibge.gov.br/agencia-sala-de-imprensa/2013-agencia-de-noticias/releases/20232-estatisticas-de-genero-responsabilidadepor-afazeres-afeta-insercao-das-mulheres-no-mercado-de-trabalho

Lessa, S. C. F. (2011). Os reflexos da legislação de educação a distância no Brasil. Faculdade Interativa COC - Polo de Aracaju, SE. Vol. 10. Disponível em: http://seer.abed.net.br/edicoes/2011/Artigo_02.pdf

Magnagnago, C. C; Ramos, M. P \& Oliveira, L. M. P. de. (2015). Estudo sobre o Uso do Moodle em Cursos de Especialização a Distância da Unifesp. Revista Brasileira de Educação Médica, 39(4), 507-516, http://www.scielo.br/pdf/rbem/v39n4/1981-5271-rbem-39-4-0507.pdf

Mill, D. \& Brito, N. D. (2009). Gestão da educação a distância: Origens e Desafios. In: CONGRESSO INTERNACIONAL ABED DE EDUCAÇÃO A DISTÂNCIA, 15, Fortaleza, 2009. Anais... CIAED, <http://www2.abed.org.br/congresso2009/CD/trabalhos/652009145737.pdf

NTE Núcleo de tecnologia educacional. (2018). Apresentação NTE. https://nte.ufsm.br/apresentacao/nte/apresentacao-nte

NTE Núcleo de tecnologia educacional. (2021) Cursos EaD. https://nte.ufsm.br/cursos

Tomelin, J. F \& Tomelin, K. N. (2017). Competências, Atribuições e Formação Continuada para Coordenadores de Curso a partir de Ambiente Virtual de Aprendizagem. In: CIAED - CONGRESSO INTERNACIONAL ABED DE EDUCAÇÃO A DISTÂNCIA, Foz do Iguaçu. Anais... 0-12. http://www.abed.org.br/congresso2017/trabalhos/pdf/127.pdf

UFSM Universidade Federal De Santa Maria. (2016). Plano de Desenvolvimento Institucional, 2016-2026. http://site.ufsm.br/arquivos/uploaded/arquiv os/0510013d-1d91-47d4-bf67-1e3120598fa6.pdf

Ventura, M. M.(1972). O Estudo de Caso como Modalidade de Pesquisa Pedagogia Médica. Socerj, 5(20), 383-396.

Knuth, D. E. (1984). The TeXbook, Addison Wesley, (15a ed.).

Peterson, L.; Dilillo, D.; Lewis, T. \& Sher, K. (2002) Improvement in quantity and quality of prevention measurement of toddler injuries and parental interventions. Behavior Therapy, 33(2), 271-297.

Smith, A., \& Jones, B. (1999) On the complexity of computing. In Advances in Computer Science, p. 555-566. Publishing Press.

Spires, H. A.; Lee, J. K., \& Lester, J. (2008). The Twenty-First Century Learner and Game-Based Learning. Meridian: a Middle School Computer Technologies Journal, 11(1), 1-4. 